\title{
Clone and Rootstock Interactions Influence the Cold Hardiness of Vitis vinifera cvs. Riesling and Sauvignon blanc
}

\author{
Andréanne Hébert-Haché, ${ }^{1}$ Debra Inglis, ${ }^{1,2}$ Belinda Kemp, ${ }^{2}$ \\ and James J. Willwerth ${ }^{1,2 *}$
}

\begin{abstract}
Cold damage is a threat to grapegrowers worldwide. Cold hardiness varies across Vitis vinifera cultivars, but the influence of clone and rootstock selection on this trait is unclear. Five clone $\times$ rootstock combinations of Riesling (clone $49 \times$ Riparia Gloire [RG], $49 \times$ SO4 Teleki, clone $239 \times$ RG, $239 \times$ SO4, and $239 \times$ Couderc 3309) and four clones of Sauvignon blanc (clone 242, 297, 376, and 530 on SO4 Teleki rootstock) were evaluated over three dormant seasons (2016/17, 2017/18, and 2018/19). Bud cold hardiness was quantified every two to four weeks by differential thermal analysis and reported as low temperature exotherms. Yield and pruning weights were determined every year. Rootstock did not influence the cold hardiness of Riesling buds consistently, although clone 239 was generally hardier than clone 49 . Significant clone $\times$ rootstock interactions were observed more frequently in the first year of the study. No consistent differences were observed between Sauvignon blanc clones, although clone 242 and 297 were often among the least-hardy clones. Differences in hardiness were not consistently related to yield, pruning weight, or crop load in the prior growing season. This study demonstrates the importance of both clone and rootstock selection in cool climate regions where freeze injury may occur. Future research should consider the clone identity and the possibility of a clone $\times$ rootstock interaction when comparing the cold hardiness of different cultivars.
\end{abstract}

Key words: clone, cold hardiness, cool climate, differential thermal analysis, rootstock, Vitis vinifera

Freezing temperatures are the most significant abiotic threat to grape production in many cool-climate regions (Fennell 2004). Grapevine cold hardiness depends on supercooling, which is the capacity to prevent freezing of intracellular water (Pierquet et al. 1977). This ability develops during endodormancy, which is first initiated by a shorter photoperiod and enhanced by decreasing temperatures (Schnabel and Wample 1987). Cold hardiness develops through acclimation, which occurs concurrently with endodormancy and can continue into ecodormancy (Cragin et al. 2017). Early acclimation is accompanied by periderm formation around the canes and de-

\footnotetext{
${ }^{1}$ Department of Biological Sciences, Brock University, 1812 Sir Isaac Brock Way, Ontario, Canada, L2S 3A1; and ${ }^{2} \mathrm{Cool}$ Climate Oenology and Viticulture Institute, Brock University, 1812 Sir Isaac Brock Way, Ontario, Canada, L2S 3A1.

*Corresponding author (jwillwerth@brocku.ca; tel: 905-688-5550 ext. 5477; fax: 905-688-3704)

Acknowledgments: This research was funded by a Natural Sciences and Engineering Research Council of Canada's Collaborative Research Development grant (CRDPJ 484050-15) and Ontario Grape and Wine Research Inc. The authors have no conflict of interest to declare. The authors thank Mary Jasinski and Stephanie Bilek for their technical assistance.

Supplemental data is freely available with the online version of this article at www.ajevonline.org.

Manuscript submitted April 2020, revised Sept 2020, Oct 2020, accepted Nov 2020

This is an open access article distributed under the CC BY license (https:// creativecommons.org/licenses/by/4.0/).

By downloading and/or receiving this article, you agree to the Disclaimer of Warranties and Liability. The full statement of the Disclaimers is available at http://www.ajevonline.org/content/proprietary-rights-notice-ajev-online. If you do not agree to the Disclaimers, do not download and/or accept this article. doi: 10.5344/ajev.2020.20025
}

creased water content in buds and canes (Wolpert and Howell 1986). Within-vine cold hardiness is not always uniform. Cane differences in periderm development, sunlight exposure, and presence of lateral shoots lead to uneven acclimation, resulting in differences of as much as $12^{\circ} \mathrm{C}$ (Howell and Shaulis 1980). The geographic location of a vineyard can also affect cold hardiness significantly (Stergios and Howell 1977).

Cold hardiness differences among cultivars are well known (Cindric and Korac 1990, Pool et al. 1990, Mills et al. 2006, Dami et al. 2016), but intra-cultivar differences are rarely studied. Rootstocks have long been thought to influence cold hardiness of scions because of their ability to mitigate many plant stresses. Rootstock-scion communication is important: the root system facilitates several physiological processes that are related to cold hardiness such as water (Tramontini et al. 2013) and nutrient uptake (Fisarakis et al. 2004), carbohydrate availability to the buds (Cox et al. 2012), and production of hormones such as abscisic acid (Stoll et al. 2000). Vine size and crop load are impacted by the rootstock (Reynolds and Wardle 2001) and are thought to decrease cold hardiness by increasing the number of canes with poor acclimation through shading effects (Striegler and Howell 1991). Mixed results have been reported in the literature on the relationship between crop load and cold hardiness; both no relationship (Dami et al. 2013, Lefebvre et al. 2015) and a negative impact of overcropping on cold hardiness (Howell et al. 1978, Dami et al. 2015) have been reported. The only reported influence of rootstock on cold hardiness is a small reduction in shootless nodes in some years when Riesling was grafted onto 3309 rootstock (Miller et al. 1988).

An effective way to maximize winter survival of specific cultivars could be identification of plant material, clones, or 
biotypes with superior cold hardiness. Clones are a potential source of genetic diversity but are not traditionally selected for their cold hardiness. Intra-cultivar phenotype differences in pruning weights, yield components, and fruit composition are common in several cultivars such as Chardonnay, Pinot noir, and Merlot (Wolpert et al. 1994, Benz et al. 2006, Castagnoli and Vasconcelos 2006, Anderson et al. 2008). To our knowledge, only Pinot noir clones have been studied in the context of cold hardiness, with clones Mariafeld, Spätburgunder, and Espinette being less tolerant, and clone 29 and Pernand having generally the smallest percentage of shootless nodes (Pool et al. 1990).

Cold hardiness to acute cold exposure can be measured directly by differential thermal analysis (DTA), which detects the low temperature exotherm (LTE) from the latent heat released when intracellular water freezes (Mills et al. 2006). Buds are placed in a programmable temperature chamber and exposed to steadily decreasing temperatures to simulate a naturally occurring cold event. As the buds reach their lethal temperature, intracellular water freezes, causing bud death. This event releases latent heat detected by a thermomodule and converted to a change in voltage that can be quantified by a multimeter. It is a destructive test that kills the buds and is directly related to cold injury (Pierquet et al. 1977, Mills et al. 2006).

Growing grapes successfully in cool climates depends on the ability of grapevines to resist winter minimal temperatures. New ways to improve cold hardiness and reduce freeze injury must be identified to ensure sustainable growing of $\mathrm{Vi}$ tis vinifera in cool climate viticultural areas such as Ontario, Canada, where climate change may increase extreme weather events such as minimal winter temperatures or spring frost. Clone and rootstock both have the potential to improve cold hardiness through direct or indirect effects. It was therefore hypothesized that clone and rootstock selection might be a significant source of intra-cultivar cold hardiness variation. To test this hypothesis, five clone and rootstock combinations of Riesling and four clones of Sauvignon blanc were sampled at regular intervals in a commercial vineyard over three dormant seasons, from acclimation to deacclimation, and their cold hardiness was quantified by DTA.

\section{Materials and Methods}

Vineyard and experimental design. This research was conducted in a commercial vineyard located in the Four Mile Creek VQA sub-appellation within the Niagara Peninsula (ON, Canada) on loam to sandy-loam soil with $1.0 \mathrm{~m}$ $\times 2.5 \mathrm{~m}$ (vine $\times$ row) spacing. Vines were trained in double cordon with vertical shoot-positioning and spur-pruned to an estimated nine viable buds/cordon following dormant bud survival assessments. Vineyard maintenance and pest management were based on normal industry standards and were consistent across the experimental site. Three randomized, replicated experimental blocks (units) per clone $\times$ rootstock combination were selected; each block containing eight 7-vine panels. Forty-four vines per block were sampled for DTA measurements, and 12 vines were flagged at random in each block to measure vine balance and yield components. Clone $\times$ rootstock combinations selected for Riesling were ENTAVINRA clone $49 \times$ Riparia Gloire $(\mathrm{RG}), 49 \times$ SO4 Teleki (SO4), clone Geisenheim $239 \times \mathrm{RG}, 239 \times \mathrm{SO} 4$, and $239 \times$ Couderc 3309 (3309). Vines were 10-years-old at the onset of the study with the exception of $239 \times 3309$, which were 19-years-old. The clones of Sauvignon blanc selected were ENTAV-INRA clones 242, 297, 376, and 530, all grafted to the SO4 rootstock and all 15-years-old at the onset of the study. Weather data was collected from a weather station within $1 \mathrm{~km}$ of the vineyard maintained by Weather Innovations Consulting Vine \& Tree fruit Innovations (http://www.vineinnovations. com). Daily growing degree days (GDD) were calculated from daily mean temperatures with a base of $10^{\circ} \mathrm{C}$, from 1 April to 31 Oct.

Cold hardiness measurement and analysis. Six canereplicates per block, from six different vines, were collected every two to four weeks from October 2016 to April 2017 for LTE measurements by DTA. The collection was replicated during the 2017 to 2018 and 2018 to 2019 dormant seasons. Frequency of sampling was greater during the acclimation and deacclimation stages. DTA was performed as described (Mills et al. 2006), with modifications. Buds from positions 3 to 7 were removed from canes in the lab and placed cutside up on the thermo electric modules (TEM) covered with a Kimwipe (Kimberley-Clark Professional) moistened with distilled water. Up to five buds were placed on each TEM. Nine TEM were set up per tray and a maximum of six trays were used in one freezer run. The temperature of the programmable temperature chamber (Tenney T2C, SPX Thermal Product Solutions) was decreased by $4^{\circ} \mathrm{C} / \mathrm{hr}$, from $4^{\circ} \mathrm{C}$ to $-40^{\circ} \mathrm{C}$, and the TEM signal was acquired throughout the run by a multimeter data acquisition system (Keithley 2700 Integra Series). The TEM voltage output versus the temperature of the tray was plotted by the software BudProcessor for each TEM (2018 version 1.7.2, Brock University). Peaks representing LTE for primary buds were identified visually on the output. Because the cold-hardiness of buds from the same cane are related, raw bud LTEs are not independent data points. The average cane LTEs were calculated and used in subsequent cold-hardiness statistical analysis.

Phenological stage monitoring. Phenological stages were monitored throughout the growing season to identify the dates of budbreak, bloom, and veraison, estimated by the date at which $50 \%$ of the vines are at the Eichhorn-Lorenz stages 4, 23, and 35, respectively, as described (Coombe 1995). To identify these stages, each block was monitored regularly. For budbreak, the number of buds beyond stage 4 was determined for seven vines/block. For bloom and veraison, 20 clusters/ block were examined and the number of clusters beyond stages 23 and 35, respectively, was determined until $>50 \%$ had reached the appropriate stage.

Yield components and vine balance. Yield component measurements were performed immediately prior to commercial harvest. Flagged vines were harvested individually to determine cluster number and vine yield. Pruning was performed on the harvested vines during the dormant seasons 
following the decisions of the vineyard manager. The weight of the pruned canes was recorded in the field. The Ravaz index (RI) was used to measure vine balance and was calculated by dividing the yield/vine by the pruning weight/vine.

Statistical analysis. All statistical analyses were carried out using XLSTAT version 2019.3.2 (Addinsoft). LTEs from Riesling clone $\times$ rootstock combinations for all dates and the yield components, pruning weights, and RIs were compared by two-way analysis of variance (ANOVA) to identify clone $\times$ rootstock interactions and the contributions of clone and rootstock factors individually. Additional one-way ANOVA were used to compare Riesling clone 239 on RG, SO4, or 3309 rootstocks for the last two years of the study to identify rootstock effect. LTEs from Sauvignon blanc and the yield components, pruning weights, and RIs were compared by one-way ANOVA. All significant ANOVA tests were followed by Tukey's honest significant difference post-hoc test.

\section{Results}

Weather conditions/vintage variation. The weather differed among the three years studied. The 2016/17 dormant season was preceded by the lowest total rainfall, with only 207 $\mathrm{mm}$ received from May to October and long periods without rainfall in May, June, and July (Figure 1). The lack of rainfall was accompanied by 42 days with a maximum temperature above $30^{\circ} \mathrm{C}$, the highest number in the three years studied. A total of 1626 GDD accumulated between 1 May 2016 and 31 Oct 2016. The 2017 growing season was wetter and colder than 2016, with more than twice as much rainfall, $444 \mathrm{~mm}$, only $1454 \mathrm{GDD}$, and 12 days with maximum temperature above $30^{\circ} \mathrm{C}$ (Figure 1). In 2018, a total of $369 \mathrm{~mm}$ of rain was received, accompanied by 1662 GDD and 34 days with temperature above $30^{\circ} \mathrm{C}$ (Figure 1). The three dormant seasons had also different temperature patterns. The 2016/17 dormant season was relatively mild, with a minimum temperature of $-13.1^{\circ} \mathrm{C}$ reached on 7 Jan 2017 . Only 12 days had minimum temperatures below $-10^{\circ} \mathrm{C}$, and important temperature fluctuations were measured (Figure 2). Some large fluctuations in temperature occurred during many periods of dormancy. The 2017/18 dormant period was colder than the preceding, with 12 days below $-15^{\circ} \mathrm{C}$, and the lowest temperature, $-19.8^{\circ} \mathrm{C}$, was recorded on 7 Jan 2018. Severe temperature fluctuations were recorded again, particularly from mid-December to the end of February (Figure 2). Fewer fluctuations in temperature were observed in 2018/19, but the coldest temperatures of the study were recorded with two days below $-20^{\circ} \mathrm{C}$ and a minimum of $-20.3^{\circ} \mathrm{C}$ on $31 \mathrm{Jan} 2019$. The temperatures were generally lower during the 2018/19 acclimation period than in the other two dormant seasons (Figure 2).

Phenology. Phenological stages were reached almost simultaneously for Riesling and Sauvignon blanc at the experimental vineyard site. Budbreak was uniform among the Sauvignon blanc clones and was observed on 13 May 2016, 10 May 2017, and 16 May 2018. Budbreak of the Riesling clone $\times$ rootstock combinations differed by one or two days, depending on the year. It was observed on 14 May for all combinations but $239 \times$ RG (16 May) in 2016, on 9 May 2017 in $49 \times \mathrm{SO} 4,239 \times \mathrm{RG}$, and $239 \times \mathrm{SO} 4$ or on 10 May for the others, and on 15 May 2018 for all combinations. Bloom was observed on 20 June 2016, 14 June 2017, and 21 June 2018 for all Sauvignon blanc and Riesling clone $\times$ rootstock combinations, and veraison was observed on 16 Aug 2016, 25 Aug 2017, and 23 Aug 2018. Any difference in timing of phenological stages at budbreak were no longer apparent by bloom or veraison in either cultivars, regardless of the clone or rootstock.

Riesling clone and rootstock comparisons. Cold hardiness. Riesling clones differed with respect to their cold hardiness late in the acclimation phase in all years studied and during deacclimation, particularly in the first two years of the
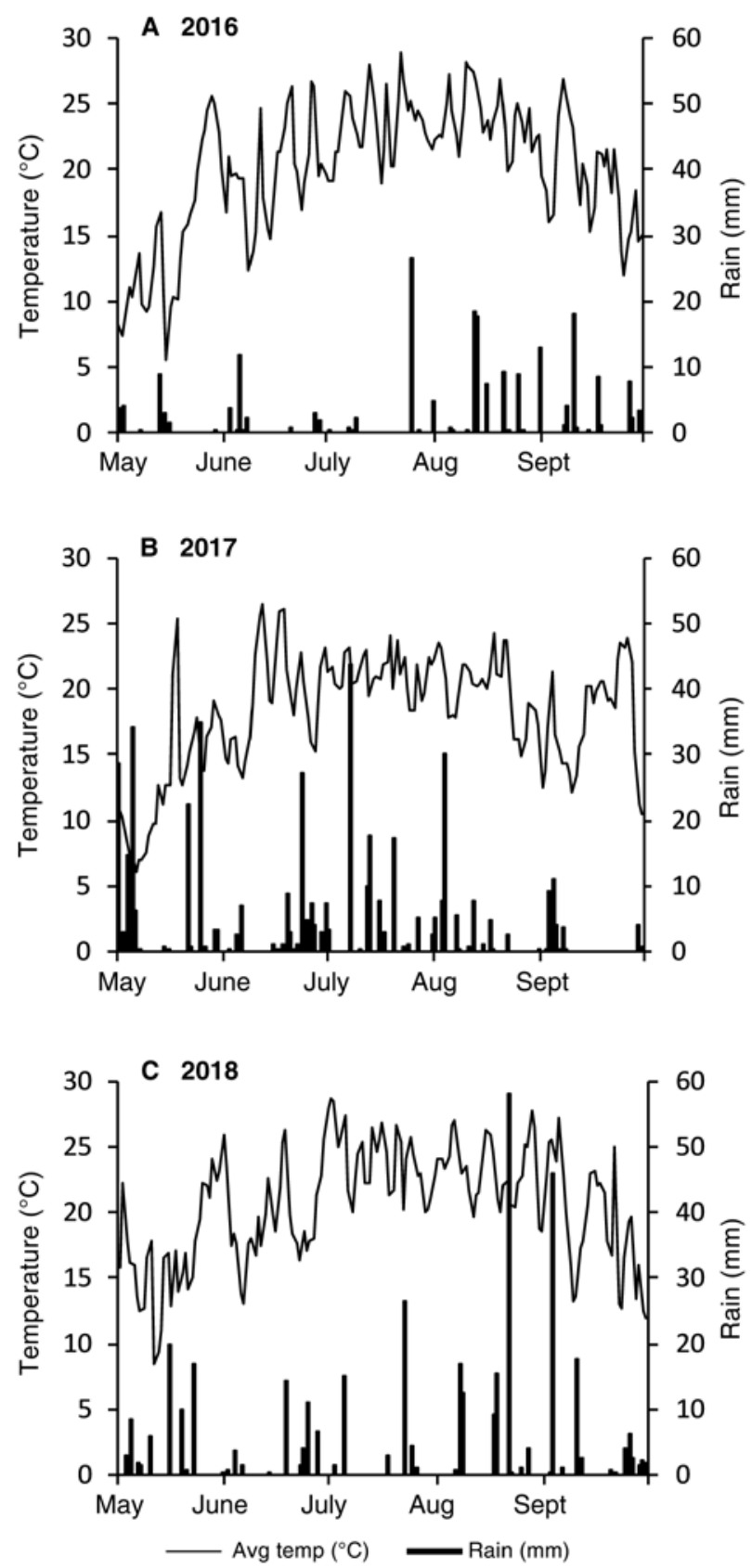

Figure 1 Average daily temperature and daily rainfall from 1 May to 30 Sept on the three growing seasons (A) 2016, (B) 2017, and (C) 2018 preceding the dormant seasons monitored in the study. 
study (Table 1). Significant differences also occurred during the maximum hardiness phase of the first year (Table 1). In general, clone 239 was hardier than clone 49. Year one had the highest proportion of dates with significant differences, followed by year two. Rootstock differences were rare to nonexistent in year one (Table 1). They occurred mostly during acclimation in year two and only during maximum hardiness in year three. No clear trend of superior hardiness emerged for the scions grafted to the RG or SO4 rootstocks comparable to that observed among clones.

The clone $\times$ rootstock interactions were significant for eight of the 12 sampling dates in the first year of the study, indicating rootstock-specific hardiness differences among clones (Table 1). Significant interactions were observed in year two during deacclimation and in year three at acclimation and at the start of deacclimation. Clone 239 was hardier when grafted to RG, but clone 49 was generally less hardy when grafted to the same rootstock (Table 1, Supplemental Figure 1).
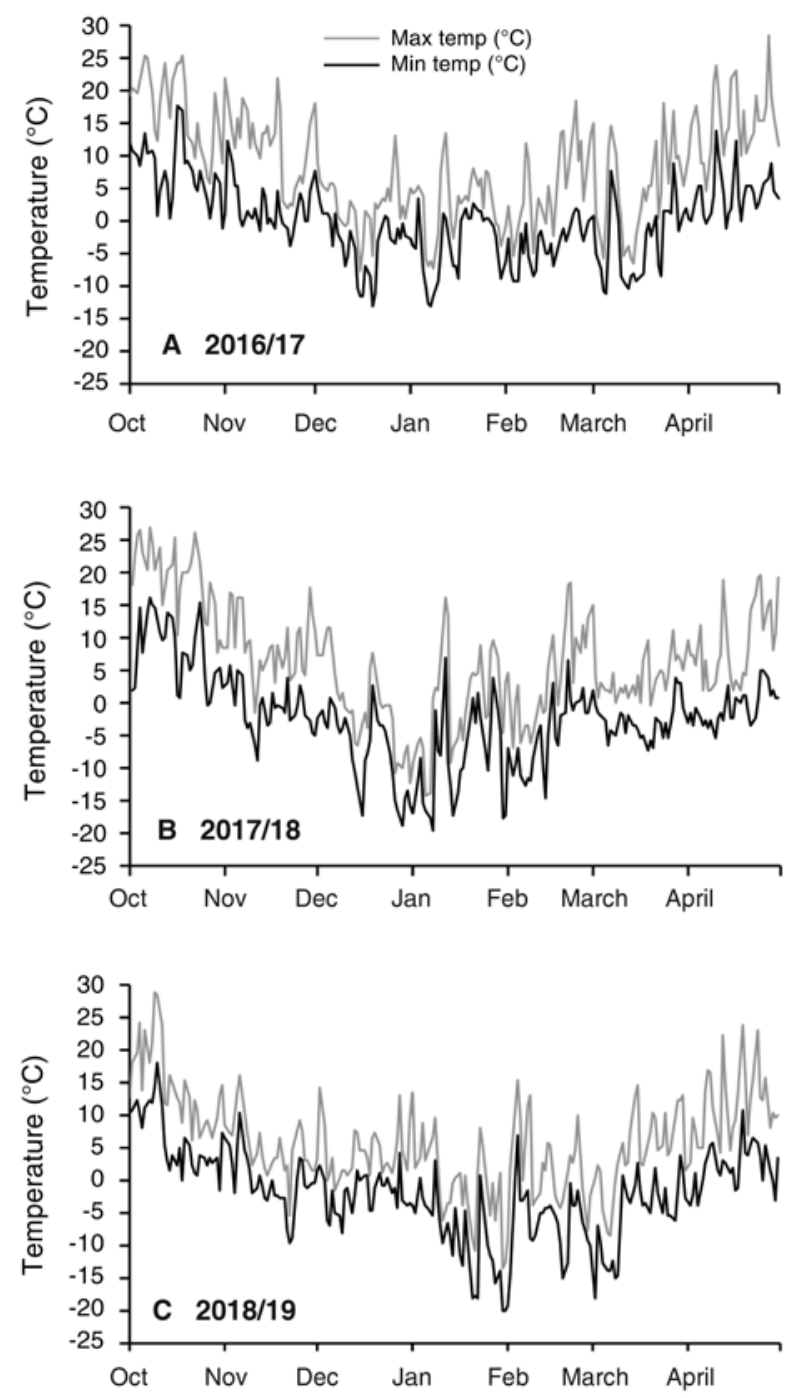

Figure 2 Maximum and minimum temperatures from 1 Oct to 30 April for the three dormant seasons (A) 2016/17, (B) 2017/18, and (C) 2018/19 monitored in the study.
Since only clone 239 was evaluated on 3309 rootstock in two of the three dormant periods, the effect of three rootstocks on cold hardiness of clone 239 was analyzed separately. In the first dormant season, $239 \times \mathrm{RG}$ appeared hardier (Supplemental Figure 2) but was rarely distinguishable statistically from $239 \times 3309$ (Table 2 ). In the second year, $239 \times \mathrm{RG}$ appeared less hardy than the other combinations (Supplemental Figure 2), but the differences were only statistically significant on two sampling dates (Table 2).

Yield and vine size. Yields, pruning weights, and RI of the clone $\times$ rootstock combinations of Riesling were compared. Clone 239 had significantly lower yield and pruning weights per vine but overall similar crop load based on RI to clone 49 (Table 3). Similarly, RG-grafted vines had lower yields and pruning weights but similar crop loads to SO4-grafted vines (Table 3). The clone $\times$ rootstock interaction was significant for pruning weights and crop load, often due to the pruning weights of the 239/RG combination, which were significantly lower than the other combinations in all years sampled (Table 3 ). When evaluating the impact of the three rootstocks on clone 239, crop load was not different between the three rootstocks, although the $239 \times 3309$ combination had lower yield and pruning weights (Table 4).

Sauvignon blanc clone comparison. Cold-hardiness. The cold-hardiness of Sauvignon blanc was inconsistent from year to year and fluctuated between sampling dates (Supplemental Figure 3). Almost no significant differences were observed in the first year of the study. Some differences in hardiness during acclimation and deacclimation were observed in years two and three, but the clones did not behave consistently (Table 5). Clones 242 and 297 were more likely to be among the least-hardy clones than clones 376 and 530 .

Yield and vine size. Clone 242 generally had greater yields and lower pruning weights than the other clones, resulting in significantly higher RI every year (Table 6). The RI for clones 297, 376, and 530 were comparable for all vintages. The very large RIs in 2016, more than double those in 2017 and four times those in 2018, were related to the smaller pruning weights and greater yields for that dormant season.

Cultivar differences. As expected, Riesling was more cold-hardy than Sauvignon blanc on every date in all years sampled (Figure 3). The difference between the 25th and the 75th quartile was generally smaller for Riesling than for Sauvignon blanc. The middle $50 \%$ of the LTE for Riesling generally spanned over 2 to $3^{\circ} \mathrm{C}$, and this was consistent from year to year. Conversely, the spread of the Sauvignon blanc exotherms was larger and showed vintage variation. The greatest spread of exotherm data occurred in the 2016/17 dormant season (Figure 3), where differences of up to $8^{\circ} \mathrm{C}$ were recorded. The differences between the 25 th and the 75 th quartiles were similar in Sauvignon blanc and Riesling in the 2018/19 dormant season.

\section{Discussion}

This study investigated the cold-hardiness of Riesling and Sauvignon blanc by evaluating five clone $\times$ rootstock combinations of Riesling and four clones of Sauvignon blanc 
using DTA over three dormant seasons. While cold hardiness research often focuses on inter-cultivar differences, the influence of clones, rootstocks, and their combinations on cold-hardiness phenotypes of $V$. vinifera has not been widely studied.

Riesling clones. This study confirmed the hypothesis that clones within a cultivar can vary in cold hardiness. When significant differences among clones were observed, clone 239 was generally hardier than clone 49 , regardless of rootstock. Differences were observed in all three years during late acclimation and deacclimation, but maximum hardiness differences were vintage-dependent. The clones had different levels of vigor and yield even though they were in the same vineyard, with consistent management practices across all combinations. Vine balance measured by the RI was significantly different only in 2016, but the average of all years indicated that clone 239 carried a greater crop load than clone 49 , mostly due to lower pruning weights. $V$. vinifera cultivars with an RI between 5 and 10 are considered in balance (Bravdo et al. 1984), and the Riesling clones were generally within these limits. The relationship between crop load and cold hardiness is variable and depends on crop size, vine vigor, and environmental conditions that impact grapevine hardiness responses. Previous research involving crop load manipulation by cluster thinning found no difference in cold hardiness between control and thinned $V$. vinifera vines with an RI in the desired range or below (Lefebvre et al. 2015) or between Vidal vines that were considered in balance and slightly overcropped (Dami et al. 2013). Reports of a negative correlation between cold hardiness and crop load have been explained by overcropping and incomplete cane lignification (Dami et al. 2005). It is therefore unlikely that the superior

Table 1 Comparison of low temperature exotherms by two-way analysis of variance (ANOVA) for Riesling clone $\times$ rootstock combinations (Clone 49 × Riparia Gloire: 49/RG; Clone 49 × SO4 Teleki: 49/SO4; Clone 239 × Riparia Gloire: 239/RG; Clone $239 \times$ SO4 Teleki: 239/SO4) in three dormant seasons (2016/17, 2017/18, and 2018/19).

\begin{tabular}{|c|c|c|c|c|c|c|c|c|c|c|c|c|}
\hline $2016 / 2017$ & 6 Oct & $180 \mathrm{ct}$ & 2 Nov & 16 Nov & 30 Nov & $14 \mathrm{Dec}$ & 4 Jan & 26 Jan & $14 \mathrm{Feb}$ & 1 March & 19 March & 1 April \\
\hline \multicolumn{13}{|c|}{ Clone/Rootstock } \\
\hline 49/RG & -10.1 & -10.4 & -12.4 & $-15.1 \mathrm{a}^{\mathrm{a}}$ & $-18.6 \mathrm{a}$ & $-20.9 a$ & $-20.7 \mathrm{a}$ & $-21.5 a$ & $-20.9 a$ & -18.2 & -18.9 a & $-15.0 \mathrm{a}$ \\
\hline $49 / \mathrm{SO} 4$ & -9.9 & -10.7 & -13.2 & $-15.7 a b$ & $-19.3 b$ & $-22.4 b$ & $-22.2 b$ & $-22.8 b c$ & $-22.5 b$ & -19.4 & $-19.9 a b$ & $-16.7 b$ \\
\hline 239/RG & -10.4 & -12.0 & -13.0 & $-17.2 \mathrm{c}$ & $-20.5 c$ & $-22.4 b$ & $-23.6 c$ & $-23.4 c$ & $-24.0 c$ & -20.2 & $-20.6 b$ & $-18.0 c$ \\
\hline 239/SO4 & -10.2 & -11.3 & -13.3 & $-16.4 b$ & $-19.2 a b$ & $-20.9 a$ & $-22.9 b c$ & $-21.9 a b$ & $-22.7 b$ & -19.8 & $-20.1 b$ & $-17.7 b c$ \\
\hline $\begin{array}{l}\text { Clone } \times \\
\text { rootstock } \\
\text { interaction }\end{array}$ & $n s^{b}$ & ns & ns & * & $\star \star \star \star *$ & $* * *$ & $* \star *$ & $* \star *$ & $\star * \star *$ & ns & * & ** \\
\hline Clone factor & ns & $* *$ & ns & 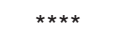 & $\star \star * *$ & ns & 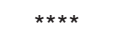 & ns & 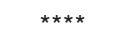 & $* * *$ & ** & 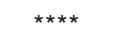 \\
\hline $\begin{array}{l}\text { Rootstock } \\
\text { factor }\end{array}$ & ns & ns & ns & ns & ns & ns & ns & ns & ns & ns & ns & ns \\
\hline 2017/2018 & 29 Oct & 10 Nov & 24 Nov & $11 \mathrm{Dec}$ & $20 \mathrm{Dec}$ & 8 Jan & 29 Jan & $14 \mathrm{Feb}$ & 8 March & 26 March & & \\
\hline \multicolumn{13}{|c|}{ Clone/Rootstock } \\
\hline 49/RG & -13.5 & -14.6 & -18.8 & -21.6 & -22.1 & -22.0 & -22.1 & -23.2 & $-21.2 \mathrm{a}$ & $-21.4 \mathrm{a}$ & & \\
\hline 49/SO4 & -12.8 & -16.4 & -19.0 & -20.8 & -22.8 & -20.2 & -22.8 & -22.8 & $-21.7 \mathrm{a}$ & $-22.1 \mathrm{a}$ & & \\
\hline 239/RG & -13.5 & -17.7 & -20.9 & -22.8 & -23.0 & -22.3 & -22.7 & -24.4 & $-23.1 c$ & $-22.1 \mathrm{a}$ & & \\
\hline 239/SO4 & -12.4 & -18.3 & -20.9 & -22.4 & -23.0 & -22.1 & -22.7 & -23.5 & $-22.3 b$ & $-21.6 a$ & & \\
\hline $\begin{array}{l}\text { Clone } \times \\
\text { rootstock } \\
\text { interaction }\end{array}$ & ns & ns & ns & ns & ns & ns & ns & ns & ** & * & & \\
\hline Clone factor & ns & $* * * *$ & $* * * *$ & $* * * *$ & ns & ns & ns & $* * *$ & $\star * \star \star *$ & ns & & \\
\hline $\begin{array}{l}\text { Rootstock } \\
\text { factor }\end{array}$ & ** & $* *$ & $\mathrm{~ns}$ & * & ns & ns & ns & $* *$ & ns & ns & & \\
\hline 2018/2019 & 3 Oct & 19 Oct & 30 Oct & 12 Nov & 27 Nov & $18 \mathrm{Dec}$ & 11 Jan & $1 \mathrm{Feb}$ & $19 \mathrm{Feb}$ & 5 March & 18 March & \\
\hline \multicolumn{13}{|c|}{ Clone/Rootstock } \\
\hline 49/RG & $-10.5 a$ & -12.7 & -13.2 & -17.5 & -19.6 & -21.8 & -23.0 & -22.9 & $-22.4 \mathrm{a}$ & -22.3 & -21.8 & \\
\hline $49 / \mathrm{SO} 4$ & $-11.9 b$ & -13.1 & -12.7 & -16.6 & -20.5 & -21.7 & -24.0 & -23.8 & $-23.7 b$ & -23.3 & -22.5 & \\
\hline 239/RG & $-11.0 a b$ & -12.8 & -13.4 & -18.6 & -21.5 & -23.2 & -22.7 & -23.9 & $-23.1 a b$ & -23.6 & -22.5 & \\
\hline $239 / \mathrm{SO} 4$ & $-10.6 \mathrm{a}$ & -13.3 & -13.7 & -17.9 & -21.6 & -23.1 & -24.0 & -24.5 & $-23.1 a b$ & -22.9 & -22.9 & \\
\hline $\begin{array}{l}\text { Clone } \times \\
\text { rootstock } \\
\text { interaction }\end{array}$ & * & ns & ns & ns & ns & ns & ns & ns & * & ns & ns & \\
\hline Clone factor & ns & ns & ns & ** & $* * * *$ & $* * \star *$ & ns & ns & ns & ns & * & \\
\hline $\begin{array}{l}\text { Rootstock } \\
\text { factor }\end{array}$ & ns & ns & ns & ns & ns & ns & ** & ns & * & ns & ns & \\
\hline
\end{tabular}

aMeans followed by different letters are significantly different $(p<0.05)$ for the date within a factor separated by Tukey's honest significant difference post-hoc test.

${ }^{\text {b }}$ Significance level of the two-way ANOVA indicating difference at ${ }^{*}: p<0.05 ;{ }^{* *}: p<0.01 ;{ }^{* *}: p<0.001 ;{ }^{* * * *}: p<0.0001 ;$ or no significant difference: ns. 
hardiness of clone 239 was caused by the greater RI or lower yield and pruning weights reported in this study.

The Riesling clones selected for this study come from different breeding programs. Clone 49 is an ENTAV-INRA clone that was certified in 1971 in Alsace, while clone 239 is a Geisenheim clone originating from Germany. Certain clones of Riesling show enough genetic variability to make them differentiable and identifiable using appropriate genetic markers (Regner et al. 2000). Moreover, accessions with different geographic origins can be differentiated by a combination of genetic tests (Meneghetti et al. 2012), demonstrating the impact of the origin of the clone on the genotype. Although genetic testing would be necessary to confirm this hypothesis, the clones in this study could have a high degree of genetic diversity, particularly considering their diverse geographic origins. This diversity could lead to the cold-hardiness phe- notype differences observed. Differential gene expression during endodormancy or a greater production of cold-protecting metabolites could lead to the superior hardiness of clone 239 throughout the dormant season, but this hypothesis has not been confirmed.

Influence of rootstock and clone $\times$ rootstock interactions in Riesling. Rootstocks did not appear to contribute to the cold-hardiness of the scions. The DTA differences between RG and SO4-grafted clones 239 and clone 49 were inconsistent across years and rarely significant. The same observations were true for clone 239 grafted to RG, SO4, and 3309. While minor differences were measured by DTA, the rootstocks influenced yield, pruning weights, and RI in most years for both clones as expected. Yields and pruning weights were equal or greater for the clones grafted to the $\mathrm{SO} 4$ rootstock, while crop load was greater on vines grafted

\begin{tabular}{|c|c|c|c|c|c|c|c|c|c|c|c|}
\hline $2017 / 2018$ & 29 Oct & 10 Nov & 24 Nov & $11 \mathrm{Dec}$ & $20 \mathrm{Dec}$ & 8 Jan & 29 Jan & $14 \mathrm{Feb}$ & 8 March & 26 March & \\
\hline \multicolumn{12}{|c|}{ Clone/rootstock } \\
\hline 239/RG & $-13.4 b^{a}$ & -17.7 & -20.9 & -22.9 & -23.0 & -22.4 & -22.8 & $-24.4 b$ & $-23.1 b$ & -22.1 & \\
\hline 239/SO4 & $-12.5 \mathrm{a}$ & -18.0 & -20.9 & -22.4 & -23.0 & -22.0 & -22.6 & $-23.4 \mathrm{a}$ & $-22.3 \mathrm{a}$ & -21.7 & \\
\hline 239/3309 & $-13.2 a b$ & -17.2 & -20.7 & -22.5 & -23.1 & -21.5 & -23.2 & $-23.9 a b$ & $-22.1 \mathrm{a}$ & -21.6 & \\
\hline Significance $^{b}$ & * & ns & ns & ns & ns & ns & ns & * & $* * *$ & ns & \\
\hline 2018/2019 & 3 Oct & 19 Oct & 30 Oct & 12 Nov & 27 Nov & $18 \mathrm{Dec}$ & 11 Jan & $1 \mathrm{Feb}$ & 19 Feb & 5 March & $18 \mathrm{March}$ \\
\hline \multicolumn{12}{|c|}{ Clone/rootstock } \\
\hline 239/RG & -10.9 & $-13.1 \mathrm{a}$ & -13.4 & -18.6 & -21.6 & -23.2 & $-22.7 \mathrm{a}$ & -23.8 & -23.0 & -23.6 & -22.5 \\
\hline 239/SO4 & -10.6 & $-13.2 \mathrm{a}$ & -13.6 & -17.9 & -21.6 & -23.1 & $-24.0 b$ & -24.5 & -23.1 & -22.9 & -22.9 \\
\hline 239/3309 & -11.3 & $-14.4 b$ & -13.8 & -18.1 & -21.4 & -23.1 & $-23.7 b$ & -24.4 & -24.0 & -23.2 & -22.6 \\
\hline Significance & ns & * & ns & ns & ns & ns & $* * *$ & ns & ns & ns & ns \\
\hline
\end{tabular}

aMeans followed by different letters are significantly different $(p<0.05)$, separated by Tukey's honest significant difference post-hoc test. ${ }^{b}$ Significance level of the one-way ANOVA indicating difference at ${ }^{*}: p<0.05 ;{ }^{* *}: p<0.001$; or no significant difference: ns.

Table 3 Comparison of yield, pruning weights, and Ravaz index by two-way analysis of variance (ANOVA) for Riesling clones 49 and 239 grafted to Riparia Gloire and SO4 Teleki (49/RG, 49/SO4; 239/RG, 239/SO4) in three years and the average of all years.

\begin{tabular}{|c|c|c|c|c|c|c|c|c|c|c|c|c|}
\hline \multirow[b]{2}{*}{ Factor } & \multicolumn{4}{|c|}{ Yield (kg/vine) } & \multicolumn{4}{|c|}{ Pruning weights (kg/vine) } & \multicolumn{4}{|c|}{ Ravaz index } \\
\hline & 2016 & 2017 & 2018 & All years & 2016 & 2017 & 2018 & All years & 2016 & 2017 & 2018 & All years \\
\hline \multicolumn{13}{|l|}{ Clone } \\
\hline 49 & 3.3 & 4.7 & 3.3 & 3.8 & 0.46 & 0.57 & 0.55 & 0.53 & 7.8 & 9.3 & 6.2 & 7.8 \\
\hline 239 & 3.1 & 3.9 & 2.7 & 3.2 & 0.38 & 0.42 & 0.50 & 0.44 & 9.8 & 10.3 & 5.7 & 8.6 \\
\hline Significance ${ }^{a}$ & ns & $* * \star *$ & $* \star *$ & $* * \star *$ & $\star *$ & $* * * *$ & * & $* * * *$ & $\star *$ & ns & ns & * \\
\hline \multicolumn{13}{|l|}{ Rootstock } \\
\hline$R G$ & 3.0 & 4.1 & 2.9 & 3.3 & 0.41 & 0.50 & 0.47 & 0.46 & 8.9 & 9.4 & 6.6 & 8.3 \\
\hline $\mathrm{SO} 4$ & 3.4 & 4.5 & 3.0 & 3.6 & 0.43 & 0.49 & 0.59 & 0.50 & 8.6 & 10.2 & 5.3 & 8.0 \\
\hline Significance & $* *$ & * & ns & $* * *$ & ns & ns & $* \star \star \star *$ & $* *$ & ns & ns & $* * *$ & ns \\
\hline \multicolumn{13}{|c|}{$\begin{array}{l}\text { Clone } \times \text { rootstock } \\
\text { interaction }\end{array}$} \\
\hline $49 / R G$ & 3.3 & 4.4 & $3.4 \mathrm{a}^{\mathrm{b}}$ & 3.7 & $0.50 \mathrm{a}$ & $0.62 \mathrm{a}$ & $0.54 \mathrm{a}$ & $0.55 \mathrm{a}$ & 7.3 & $8.1 \mathrm{~b}$ & 6.6 & $7.3 \mathrm{~b}$ \\
\hline 49/SO4 & 3.4 & 5.0 & $3.2 \mathrm{a}$ & 3.8 & $0.43 a b$ & $0.52 a b$ & $0.57 \mathrm{a}$ & $0.51 \mathrm{a}$ & 8.3 & $10.5 a b$ & 5.9 & $8.2 a b$ \\
\hline 239/RG & 2.8 & 3.7 & $2.4 \mathrm{~b}$ & 3.0 & $0.33 \mathrm{~b}$ & $0.38 \mathrm{c}$ & $0.40 \mathrm{~b}$ & $0.37 \mathrm{~b}$ & 10.5 & $10.8 \mathrm{a}$ & 6.6 & $9.3 \mathrm{a}$ \\
\hline 239/SO4 & 3.4 & 4.1 & $2.9 a b$ & 3.5 & $0.43 a b$ & $0.46 \mathrm{bc}$ & $0.61 \mathrm{a}$ & $0.50 \mathrm{a}$ & 9.0 & $9.8 a b$ & 4.8 & $7.9 \mathrm{~b}$ \\
\hline Significance & ns & ns & * & ns & ** & ** & $* * *$ & $* * * *$ & ns & * & ns & $\star * *$ \\
\hline
\end{tabular}

aSignificance level of the two-way ANOVA indicating difference at ${ }^{*}: p<0.05 ;{ }^{* *}: p<0.01 ;{ }^{* * *}: p<0.001 ;{ }^{* * *}: p<0.0001 ;$ or no significant difference: ns.

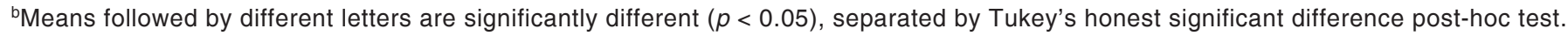


on $\mathrm{RG}$, as a result of smaller vines produced, when significant differences were reported. The RI indicated that all grafted combinations were in balance for all three years of study (Bravdo et al. 1984). Using primary bud survival of Riesling as a measure of cold hardiness, a previous study identified
3309 as better suited than SO4 to the colder climate (Miller et al. 1988), but this conclusion was not confirmed by our study.

Clone $\times$ rootstock interactions for cold hardiness were particularly important in the first year of the study, indicating that the clones performed differently on SO4 and RG

Table 4 Comparison of yield, pruning weights, and Ravaz index by one-way analysis of variance (ANOVA) for Riesling 239 grafted to Riparia Gloire (239/RG), SO4 Teleki (239/SO4), and Couderc 3309 (239/3309) in two years and the average of both years.

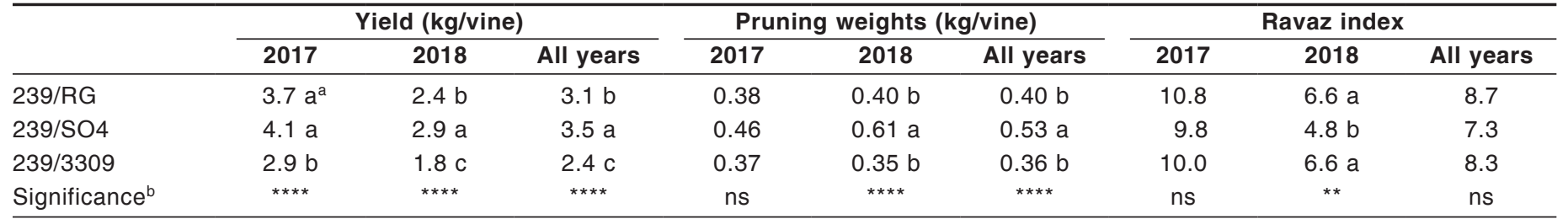

aMeans followed by different letters are significantly different $(p<0.05)$, separated by Tukey's honest significant difference post-hoc test. ${ }^{b}$ Significance level of the one-way ANOVA indicating difference at ${ }^{* *}: p<0.01$; ${ }^{* \star *}: p<0.0001$; or no significant difference: ns.

Table 5 Comparison of low temperature exotherms by one-way analysis of variance (ANOVA) for Sauvignon blanc clones grafted to SO4 Teleki rootstock.

\begin{tabular}{|c|c|c|c|c|c|c|c|c|c|c|c|c|}
\hline $2016 / 2017$ & 6 Oct & 18 Oct & 2 Nov & 16 Nov & 30 Nov & $14 \mathrm{Dec}$ & 4 Jan & 26 Jan & $14 \mathrm{Feb}$ & 1 March & 19 March & 1 April \\
\hline \multicolumn{13}{|l|}{ Clone } \\
\hline 242 & $-7.2 a b^{a}$ & -10.0 & -10.1 & -12.3 & -14.9 & -17.4 & -15.1 & -16.9 & -17.9 & -17.0 & -15.7 & -17.0 \\
\hline 297 & $-7.8 \mathrm{~b}$ & -9.7 & -9.3 & -13.1 & -13.7 & -16.6 & -14.9 & -17.7 & -16.2 & -17.2 & -15.6 & -14.7 \\
\hline 376 & $-7.8 \mathrm{~b}$ & -8.9 & -10.2 & -12.7 & -14.3 & -15.7 & -16.2 & -17.4 & -15.8 & -16.5 & -17.0 & -16.8 \\
\hline 530 & $-6.4 a$ & -9.4 & -9.7 & -12.0 & -15.0 & -17.3 & -16.9 & -18.5 & -16.6 & -16.2 & -16.9 & -16.1 \\
\hline Significance $^{b}$ & * & ns & ns & ns & ns & ns & ns & ns & ns & ns & ns & ns \\
\hline $2017 / 2018$ & 29 Oct & 10 Nov & 24 Nov & $11 \mathrm{Dec}$ & $20 \mathrm{Dec}$ & 8 Jan & 29 Jan & $14 \mathrm{Feb}$ & 8 March & 26 March & 13 April & \\
\hline 242 & -10.3 & $-12.6 b$ & $-14.2 \mathrm{a}$ & $-14.9 a$ & -16.6 & -18.0 & -19.9 & $-20.3 b$ & -20.6 & -19.8 & -15.6 & \\
\hline 297 & -9.4 & $-10.9 a$ & $-14.2 \mathrm{a}$ & $-18.0 b$ & -16.7 & -16.9 & -20.0 & $-18.1 \mathrm{a}$ & -16.8 & -20.0 & -16.3 & \\
\hline 376 & -9.3 & $-13.1 b$ & $-16.9 b$ & $-16.9 a b$ & -15.7 & -19.6 & -19.0 & $-17.2 \mathrm{a}$ & -18.1 & -18.5 & -16.3 & \\
\hline 530 & -10.1 & $-14.0 b$ & $-15.5 a b$ & $-16.7 a b$ & -17.5 & -19.7 & -19.5 & $-18.9 a b$ & -17.9 & -20.2 & -18.5 & \\
\hline Significance & ns & $\star * \star$ & $* * *$ & * & ns & ns & ns & * & ns & ns & ns & \\
\hline $2018 / 2019$ & 3 Oct & 19 Oct & $30 \mathrm{Oct}$ & 12 Nov & 27 Nov & $18 \mathrm{Dec}$ & 11 Jan & $1 \mathrm{Feb}$ & $19 \mathrm{Feb}$ & 5 March & 18 March & 13 April \\
\hline 242 & $-8.5 \mathrm{a}$ & $-11.9 b$ & -11.6 & $-14.6 b$ & $-16.6 \mathrm{a}$ & $-18.3 a$ & -19.4 & -21.2 & -19.7 & -19.2 & $-16.4 \mathrm{a}$ & $-10.2 \mathrm{a}$ \\
\hline 297 & $-8.8 a$ & $-10.7 \mathrm{a}$ & -11.3 & $-13.6 \mathrm{a}$ & $-17.0 \mathrm{a}$ & $-20.3 b$ & -20.5 & -21.3 & -19.2 & -19.0 & $-17.7 a b$ & $-11.9 b$ \\
\hline 376 & $-9.7 b$ & $-10.7 a$ & -12.3 & $-15.3 b$ & $-17.4 a b$ & $-20.6 b$ & -19.8 & -21.4 & -19.2 & -18.9 & $-18.4 b$ & $-10.1 a$ \\
\hline 530 & $-9.6 b$ & $-10.9 a$ & -11.7 & $-15.3 b$ & $-18.7 b$ & $-19.7 b$ & -20.2 & -22.0 & -18.7 & -19.5 & $-17.1 a b$ & $-9.4 \mathrm{a}$ \\
\hline Significance & $* *$ & ** & ns & $* * * *$ & ** & $* * *$ & ns & ns & ns & ns & * & * \\
\hline
\end{tabular}

a Means followed by different letters are significantly different $(p<0.05)$ for the date separated by Tukey's honest significant difference posthoc test.

${ }^{b}$ Significance level of the one-way ANOVA indicating difference at ${ }^{*}: p<0.05 ;{ }^{* *}: p<0.01 ;{ }^{* *}: p<0.001 ;{ }^{* * *}: p<0.0001 ;$ or no significant difference: ns.

Table 6 Comparison of yield, pruning weight, and Ravaz index for the Sauvignon blanc clones grafted to SO4 Teleki rootstock in three years and the average of all years.

\begin{tabular}{|c|c|c|c|c|c|c|c|c|c|c|c|c|}
\hline \multirow[b]{2}{*}{ Clone } & \multicolumn{4}{|c|}{ Yield (kg/vine) } & \multicolumn{4}{|c|}{ Pruning weight (kg/vine) } & \multicolumn{4}{|c|}{ Ravaz index } \\
\hline & 2016 & 2017 & 2018 & All years & 2016 & 2017 & 2018 & All years & 2016 & 2017 & 2018 & All years \\
\hline 242 & 3.0 & 2.6 & $1.5 \mathrm{a}^{\mathrm{a}}$ & $2.4 \mathrm{a}$ & $0.08 \mathrm{c}$ & $0.15 \mathrm{c}$ & $0.30 \mathrm{~b}$ & $0.16 \mathrm{c}$ & $53.1 \mathrm{a}$ & $20.1 \mathrm{a}$ & $5.2 \mathrm{a}$ & $25.9 \mathrm{a}$ \\
\hline 297 & 3.0 & 2.1 & $1.0 \mathrm{ab}$ & $2.0 \mathrm{~b}$ & $0.12 \mathrm{bc}$ & $0.17 \mathrm{bc}$ & $0.40 \mathrm{a}$ & $0.23 \mathrm{~b}$ & $29.4 b$ & $14.0 \mathrm{~b}$ & $2.7 \mathrm{~b}$ & $15.4 \mathrm{~b}$ \\
\hline 376 & 3.2 & 2.1 & $0.9 \mathrm{~b}$ & $2.1 \mathrm{~b}$ & $0.19 \mathrm{a}$ & $0.23 \mathrm{a}$ & $0.41 \mathrm{a}$ & $0.28 \mathrm{a}$ & $22.0 \mathrm{~b}$ & $10.6 \mathrm{~b}$ & $2.6 \mathrm{~b}$ & $11.8 \mathrm{~b}$ \\
\hline 530 & 3.1 & 2.2 & $0.9 \mathrm{~b}$ & $2.1 \mathrm{~b}$ & $0.15 a b$ & $0.21 a b$ & $0.43 a$ & $0.26 a b$ & $27.7 \mathrm{~b}$ & $13.3 \mathrm{~b}$ & $2.2 \mathrm{~b}$ & $14.4 \mathrm{~b}$ \\
\hline Significance ${ }^{b}$ & ns & ns & $\star *$ & $\star *$ & $\star \star \star \star *$ & $\star \star *$ & 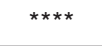 & $\star * \star *$ & $\star \star \star \star *$ & 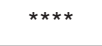 & 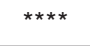 & 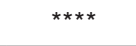 \\
\hline
\end{tabular}

${ }^{a}$ Means followed by different letters are significantly different $(p<0.05)$ for the date within a factor.

${ }^{b}$ Significance level of the one-way analysis of variance indicating difference at ${ }^{* *}: p<0.01 ;{ }^{* * *}: p<0.001 ;{ }^{* * *}: p<0.0001 ;$ or ns: no significant difference. 
rootstocks. The interaction between clone and rootstock was also significant for pruning weights in all years, but scion $\times$ rootstock combinations showed little to no difference in crop load and the vines were generally in balance. Clone 49 $\times$ RG was often significantly less hardy than $49 \times \mathrm{SO} 4$, and conversely, $239 \times \mathrm{SO} 4$ rootstock was either less hardy or equally hardy when grafted to RG. The vigor of clone $49 \times$ $\mathrm{RG}$ was also unexpectedly greater than when grafted to $\mathrm{SO} 4$ rootstock (Cousins 2005). There are important communications between rootstock and scion (Aloni et al. 2010), and some interactions resulting in reduced hardiness and overly vigorous vines may be occurring in this case. Because similar observations were not made for the combination of $239 \times \mathrm{RG}$ in the same vineyard, the observations on $49 \times \mathrm{RG}$ cannot be explained solely by soil and climate of the site.

The lack of consistent rootstock-based cold-hardiness differences in this study could be explained by the fact that complex multi-genic traits that are under scion regulation such as cold-hardiness (Wisnieswski et al. 2014) are not significantly impacted by rootstock alone when growing conditions are appropriate (Sabbatini and Howell 2013). However, specific clone $\times$ rootstock combinations may impact cold hardiness responses in selected years, and these findings require further elucidation.

Sauvignon blanc clones. Converse to Riesling, the Sauvignon blanc clones were not easily differentiated by their cold hardiness. Clones 242 and 297 were more often among the least-hardy clones, but the differences were inconsistent throughout the dormant season and across years. In general, all Sauvignon blanc clones were considered overcropped (Bravdo et al. 1984) in 2016/17. This was linked to small pruning weights rather than high yields. The clones were also considered to be overcropped in 2017 and undercropped in 2018. Clone 242 had greater yields and lower pruning weights than the other clones, but clone 297 was not differentiable from clones 376 and 530 for these traits. While this could have reduced hardiness in clone 242, crop level, pruning weights, and crop load did not affect overall cold hardiness consistently, and clone 242, at times, was the hardiest clone. The inconsistent differences in hardiness could be caused by a larger range of bud hardiness along the canes, created by uneven acclimation following unfavorable growing seasons and important overcropping practices. Bud survival can vary greatly among and within vines following improper acclimation (Howell and
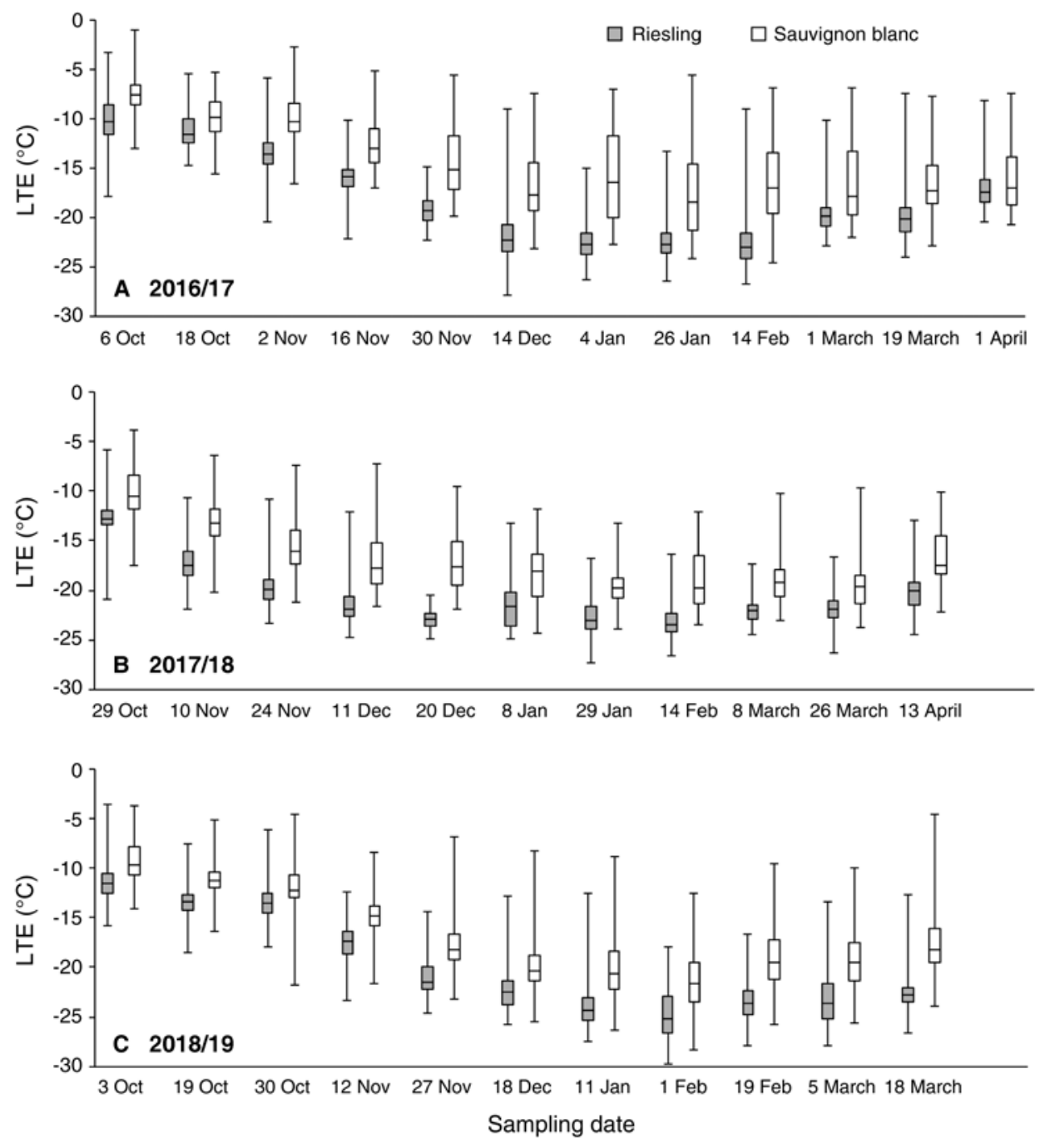

Figure 3 Pooled low temperature exotherms (LTE) from all clone and rootstock combinations for Riesling (49/RG, 49/SO4, 239/RG, 239/SO4, 239/3309) and Sauvignon blanc (242/SO4, 297/SO4, 376/SO4, 530/SO4) in (A) 2016/17, (B) 2017/18, and (C) 2018/19. The top and bottom whiskers represent the maximum and the minimum LTE, respectively. The top, median, and bottom edge of the box represent the 25th, median, and 75th quartile, respectively. 
Shaulis 1980), and practices leading to maintenance of vine size lead to superior hardiness (Howell et al. 1978). Studies typically focus on overly vigorous vines, but this study demonstrates that unbalanced, very small vines also fail to acclimate optimally and that crop load alone cannot be used to predict how relatively cold-tolerant a grapevine may be.

The Sauvignon blanc clones arose from the same breeding program; they are ENTAV-INRA clones from Alsace (http://plantgrape.plantnet-project.org/en/). All but clone 530 originated from the Loir-et-Cher vineyard between 1973 and 1975; clone 530 came from the Cher vineyard in 1976. The Sauvignon blanc clones varied from their trait descriptions at times (http://plantgrape.plantnet-project.org/en/). For example, clone 242 has previously been described by ENTAVINRA as the most vigorous clone; however, it was the least vigorous in this study. This indicates a regional effect or a potential clone $\times$ rootstock interaction between this clone and the SO4 rootstock to which it was grafted.

Cultivar differences. All clone $\times$ rootstock combinations of Riesling were hardier than the Sauvignon blanc clones at every date sampled, regardless of the dormant season, with the exception of the final sampling date in the first year of the study. The differences between the two cultivars appeared with the first DTA measurements during acclimation and were maintained during maximum hardiness and deacclimation. The superior cold hardiness of Riesling was also demonstrated when the LTE from the clone $\times$ rootstock combinations of both cultivars were pooled. Low-temperature exotherms were more tightly grouped around the median in Riesling than in Sauvignon blanc, indicating that the acclimation and cold hardiness of Riesling was more uniform, irrespective of significant clone differences. This difference was particularly large in 2016/17 and 2017/18. In the year with the most optimal acclimation weather, 2018/19, the Sauvignon blanc buds acclimated more uniformly than in the previous two years, and the clustering around the median was similar to that of Riesling. The Sauvignon blanc buds during that dormant season were sometimes as hardy as the Riesling buds, and the hardiest $25 \%$ often partially overlapped with that of Riesling. This indicates that, particularly on favorable years, Sauvignon blanc buds have the capacity to develop a more uniform and superior cold hardiness even in previously overcropped vines. The data set suggests that individual buds of Sauvignon blanc can be as cold tolerant as Riesling, but hardiness is not as uniform across the vine. These different behaviors between the cultivars could be explained by different responses to the molecular pathways leading into dormancy, but more work must be done to verify this hypothesis. Riesling is considered hardier than Sauvignon blanc, but this study demonstrates that the magnitude of this difference can be influenced by clone, rootstock selection, and by the vintage.

Weather impacts. Hardiness differences between clone and rootstock combinations varied among years in both Riesling and Sauvignon blanc. The 2016 growing season, with its dry periods, lead to important Riesling clone $\times$ rootstock interactions in the 2016/17 dormant season. The abnormal rainfall events and low GDD accumulation during the 2017 growing season preceded the dormant season with the largest clonal differences for Sauvignon blanc. Both cultivars require at least 1390 GDD to reach acceptable fruit maturity (Winkler 1962), and the important GDD differences among the years studied could have contributed to the yearly differences in cold hardiness. Optimal hardiness was observed in the 2018/19 dormant period, which had lower temperatures during acclimation than the other years studied. Considering that exposure to cold temperatures during endodormancy leads to better cold hardiness (Cragin et al. 2017), it is possible that the warmer weather during acclimation in October and November of 2016 and 2017 reduced the maximum hardiness, particularly of Sauvignon blanc. Riesling $49 \times \mathrm{RG}$ and Sauvignon blanc clone 297 were particularly sensitive to the varying weather, as demonstrated by their lower cold hardiness during the 2016/17 and 2017/18 dormant seasons, respectively. This indicates that weather events during the growing season and cold acclimation influence vine maximum hardiness, with varying impact on clone $\times$ rootstock combinations. This is an important finding, as some grafted combinations may be more resilient during dormancy under variable weather conditions, which will likely be exacerbated with climate change.

Deacclimation initiated between February and March in all years. Commercial operations in 2017/18 and 2018/19 limited observation of the full deacclimation dynamics of both Riesling and Sauvignon blanc. Vines appear to have deacclimated more rapidly in 2016/17 than any other year due to warmer temperatures in February. Seasonal variations were also expected, since temperature in the days preceding sampling dates impacts cold hardiness during maximum hardiness (Proebsting et al. 1980). Partial deacclimation and reacclimation was observed in every year of this study and was described previously (Keller et al. 2014). These patterns were more frequent in Sauvignon blanc, particularly in the 2016/17 and 2017/18 dormant seasons, putting this cultivar at a greater risk of cold damage following brief deacclimation periods. The favorable growing season and acclimation weather in the 2018/19 dormant season also led to more uniform deacclimation among the Sauvignon blanc clones.

Site differences in hardiness for the same cultivar have been reported (Dami et al. 2015). The impact of different growing seasons on cold acclimation, maximum hardiness, and deacclimation is akin to that phenomenon. Cold-tender cultivars could be more susceptible to factors impacting their cold hardiness and are more affected in unfavorable years. This could explain why the LTE differences between Riesling and Sauvignon blanc were larger in the first two years. During the rainier seasons, the soils remained quite saturated at times, even with vineyard tiling drainage installed in the Sauvignon blanc vineyard. Water-logged soils can negatively impact grapevine development (Brown et al. 2001) and health (Fisher 1997), which could result in poor cold acclimation of grapevines. This drainage issue may also explain the important lack of clonal uniformity in cold hardiness throughout the dormant season in Sauvignon blanc following the growing season with the highest precipitation. Soil moisture likely 
influences cold hardiness both directly and indirectly by encouraging late-season growth and by impacting soil temperatures in the root zone. This may be one reason for differences in performance of a given cultivar in arid regions (i.e., Pacific Northwest) than in more humid and wet regions such as Eastern North America (Bowen et al. 2016). Our study outlines the necessity of reproducing cold hardiness experiments over multiple growing seasons before drawing conclusions about the hardiness of specific cultivars or clones.

\section{Conclusion}

The purpose of this study was to characterize differences in cold hardiness among clones of Riesling and Sauvignon blanc and to understand the impact of the rootstock on specific Riesling clones. Different $V$. vinifera clones have different degrees of cold hardiness, and interaction between clone and rootstock can influence this trait. A consistent, direct influence of rootstock on cold hardiness was not observed and none of the cold hardiness differences could be explained directly by yield components, vigor, or crop load. This study also described the impact of weather on cold acclimation and uniformity of cold hardiness and demonstrated that Sauvignon blanc was more susceptible to uneven cold acclimation and climate variability than a more cold-hardy cultivar such as Riesling. Future cold hardiness studies should consider clone and rootstock interactions when comparing cultivars, should include multiple sampling dates, and should be repeated over multiple vintages. The identification of clones with superior cold hardiness could potentially be accelerated by first identifying different biotypes of cultivars originating from colder climates, where natural selection might favor development of more cold-hardy clones.

\section{Literature Cited}

Aloni B, Cohen R, Karni L, Aktas H and Edelstein M. 2010. Hormonal signaling in rootstock-scion interactions. Sci Hortic 127:119-126.

Anderson MM, Smith RJ, Williams MA and Wolpert JA. 2008. Viticultural evaluation of French and California Pinot noir clones grown for production of sparkling wine. Am J Enol Vitic 59:188-193.

Benz MJ, Anderson MM, Williams MA, Barnhisel K and Wolpert JA. 2006. Viticultural performance of five Merlot clones in Oakville, Napa Valley. Am J Enol Vitic 57:233-237.

Bowen PA, Shellie KC, Mills L, Willwerth J, Bogdanoff C and Keller M. 2016. Influence of abscisic acid form, concentration and application timing on bud cold hardiness in Merlot grapevines. Can J Plant Sci 96:347-359.

Bravdo B, Hepner Y, Loinger C, Cohen S and Tabacman H. 1984. Effect of crop level on growth, yield and wine quality of a high yielding Carignane vineyard. Am J Enol Vitic 35:247-252.

Brown M, Ferree DC, Scurlock DM and Sigel G. 2001. Impact of soil drainage on growth, productivity, cane dieback, and fruit composition of 'Chambourcin' and 'Pinot Gris' grapevines. HortTechnology 11:272-274.

Castagnoli SP and Vasconcelos MC. 2006. Field performance of 20 'Pinot noir' clones in the Willamette Valley of Oregon. HortTechnology 16:153-161.

Cindric P and Korac N. 1990. Frost resistance of grapevine cultivars of different origin. In Proceedings of the Fifth International Symposium on Grape Breeding. Vitis (Special Issue) 29:340-351.
Coombe BG. 1995. Adoption of a system for identifying grapevine growth stages. Aust J Grape Wine Res 1:104-110.

Cousins P. 2005. Evolution, genetics, and breeding: Viticultural applications of the origins of our rootstocks. In Proceedings of the 2005 Rootstock Symposium. Cousins P and Striegler RK (eds.), pp. 1-7. Southwest Missouri State University, Osage Beach, MO.

Cox CM, Favero AC, Dry PR, McCarthy MG and Collins C. 2012. Rootstock effects on primary bud necrosis, bud fertility, and carbohydrate storage in Shiraz. Am J Enol Vitic 63:277-283.

Cragin J, Serpe M, Keller M and Shellie K. 2017. Dormancy and cold hardiness transitions in winegrape cultivars Chardonnay and Cabernet Sauvignon. Am J Enol Vitic 68:195-202.

Dami IE, Ferree DC, Kurtural SK and Taylor BH. 2005. Influence of crop load on 'Chambourcin' yield, fruit quality, and winter hardiness under midwestern United States environmental. Acta Hortic 689:203-208.

Dami IE, Ennahli S and Scurlock D. 2013. A five-year study on the effect of cluster thinning and harvest date on yield, fruit composition, and cold-hardiness of 'Vidal Blanc' (Vitis spp.) for ice wine production. HortScience 48:1358-1362.

Dami IE, Li S, Bowen PA, Bogdanoff CP, Shellie KC and Willwerth J. 2015. Foliar applied abscisic acid increases 'Chardonnay' grapevine bud freezing tolerance during autumn cold acclimation. HortTechnology 25:293-305.

Dami IE, Li S and Zhang Y. 2016. Evaluation of primary bud freezing tolerance of twenty-three winegrape cultivars new to the eastern United States. Am J Enol Vitic 67:139-145.

Fennell A. 2004. Freezing tolerance and injury in grapevines. J Crop Improv 10:201-235.

Fisarakis I, Nikolaou N, Tsikalas P, Therios I and Stavrakas D. 2004. Effect of salinity and rootstock on concentration of potassium, calcium, magnesium, phosphorus, and nitrate-nitrogen in Thompson Seedless grapevine. J Plant Nutr 27:2117-2134.

Fisher HK. 1997. Drainage for optimal vineyard root growth. Wine East (April) 10-20. 41.

Howell GS and Shaulis N. 1980. Factors influencing within-vine variation in the cold resistance of cane and primary bud tissues. NY State AES Search 31:158-161.

Howell GS, Stergios BG and Stackhouse SS. 1978. Interrelation of productivity and cold hardiness of Concord grapevines. Am J Enol Vitic 29:187-191.

Keller M, Mills LJ and Olmstead MA. 2014. Fruit ripening has little influence on grapevine cold acclimation. Am J Enol Vitic 65:417-423.

Lefebvre R, Reynolds AG and Diprofio FD. 2015. Crop load and harvest date have minimal impact on bud cold hardiness and cane carbohydrate levels of four grapevine cultivars. Vitis 54:189-193.

Meneghetti S, Calò A and Bavaresco L. 2012. A strategy to investigate the intravarietal genetic variability in Vitis vinifera $\mathrm{L}$. for clones and biotypes identification and to correlate molecular profiles with morphological traits or geographic origins. Mol Biotechnol 52:68-81.

Miller DP, Howell GS and Striegler RK. 1988. Cane and bud hardiness of own-rooted White Riesling and scions of White Riesling and Chardonnay grafted to selected rootstocks. Am J Enol Vitic 39:60-66.

Mills LJ, Ferguson JC and Keller M. 2006. Cold-hardiness evaluation of grapevine buds and cane tissues. Am J Enol Vitic 57:194-200.

Pierquet P, Stushnoff C and Burke MJ. 1977. Low temperature exotherms in stem and bud tissues of Vitis riparia Michx [North America]. J Am Soc Hortic Sci 102:54-55.

Pool RM, Reisch BI and Welser MJ. 1990. Use of differential thermal analysis to quantify bud cold hardiness of grape selections and clones. Vitis 29:318-329. 
Proebsting EL, Ahmedullah M and Brummund VP. 1980. Seasonal changes in low temperature resistance of grape buds. Am J Enol Vitic 31:329-336.

Regner F, Wiedeck E and Stadlbauer A. 2000. Differentiation and identification of White Riesling clones by genetic markers. Vitis 39:103-107.

Reynolds AG and Wardle DA. 2001. Rootstocks impact vine performance and fruit composition of grapes in British Columbia. HortTechnology 11:419-427.

Sabbatini P and Howell GS. 2013. Rootstock scion interaction and effects on vine vigor, phenology, and cold hardiness of interspecific hybrid grape cultivars (Vitis spp.). Int J Fuit Sci 13:466-477.

Schnabel BJ and Wample RL. 1987. Dormancy and cold hardiness in Vitis vinifera L. cv. White Riesling as influenced by photoperiod and temperature. Am J Enol Vitic 38:265-272.

Stergios BG and Howell GS. 1977. Effects of defoliation, trellis height, and cropping stress on the cold hardiness of Concord grapevines. Am J Enol Vitic 28:34-42.

Stoll M, Loveys BR and Dry PR. 2000. Hormonal changes induced by partial rootzone drying of irrigated grapevine. J Exp Bot 51:1627-1634.
Striegler RK and Howell GS. 1991. The influence of rootstock on the cold hardiness of Seyval grapevines. 1. Primary and secondary effects on growth, canopy development, yield, fruit-quality and cold hardiness. Vitis 30:1-10.

Tramontini S, Vitali M, Centioni L, Schubert A and Lovisolo C. 2013. Rootstock control of scion response to water stress in grapevine. Environ Exp Bot 93:20-26.

Winkler AJ. 1962. General Viticulture. University of California Press, Berkeley, CA.

Wisniewski M, Nassuth A, Teulières C, Marque C, Rowland J, Cao PB and Brown A. 2014. Genomics of cold hardiness in woody plants. Crit Rev Plant Sci 33:92-124.

Wolpert JA and Howell GS. 1986. Cold acclimation of Concord grapevines. III. Relationship between cold hardiness, tissue water content, and shoot maturation. Vitis 25:151-159.

Wolpert JA, Kasimatis AN and Weber E. 1994. Field performance of six Chardonnay clones in the Napa Valley. Am J Enol Vitic 45:393-400. 